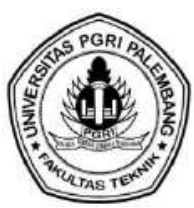

\title{
STUDI PENGARUH SATURASI AIR TERHADAP \\ PARAMETER MODULUS BULK BERDASARKAN \\ DATA SEISMIK REFRAKSI DI DAERAH \\ SOEKARNO HATTA PALEMBANG
}

\author{
Yosieguspa \\ Program Studi Teknik Sipil Fakultas Teknik \\ Universitas Islam Ogan Komering Ilir Kayuagung \\ Email :Yosieguspa@yahoo.com
}

\begin{abstract}
ABSTRAK
Penelitian ini bertujuan untuk melihat pengaruh saturasi air terhadap parameter Modulus Bulk berdasarkan data seismik. Penelitian ini berlokasi pada daerah perencanaan pembangunan kawasan industri dan perumahan didaerah Soekarno Hatta Palembang. Model penembakkan dengan cara pemukulan coupling plate serta letak geophone dalam arah vertikal dan horizontal, dan untuk mengestimasi porositas dilakukan dengan cara mengukur sampel tanah dari tiap lokasi penelitian. Nilai rata - rata Modulus Bulk yang didapat dari lokasi lapisan pertama 86315,87 Pa dan kedua 257465 Pa sebanding dengan kecepatan rata rata gelombang $P$ lokasi lapisan pertama $363,65 \mathrm{~m} / \mathrm{s}$ dan kedua $565,8 \mathrm{~m} / \mathrm{s}$, gelombang $S$ pada lapisan pertama sebesar $231,35 \mathrm{~m} / \mathrm{s}$ dan pada lapisan kedua sebesar $357,15 \mathrm{~m} / \mathrm{s}$. Hal itu secara nyata dapat membedakan tingkat kekompakkan maupun kandungan fluida pada batuan sedimen dangkal.
\end{abstract}

Kata Kunci: Saturasi Air, Model Penembakan, Modulus Bulk

\section{PENDAHULUAN}

Disamping digunakan untuk eksplorasi sumber daya alam dan menampilkan informasi tentang struktur serta distribusi tipe batuan. Akhir - akhir ini metode seismik telah berkembang untuk pengukuran parameter mekanik untuk blok massa batuan berdasarkan harga cepat rambat batuan secara insitu, termasuk didalamnya antara lain kekuatan batuan (ripability), derajat kehancuran batuan (fractured).

Studi bawah permukaan untuk karakteristik batuan dengan menggunakan sifat refleksi dan sifat reflaksi gelombang P telah banyak dilakukan oleh para ahli. (Stepples, et al; 1997; Tychen, at al, 1990, Lankton, 1990). Studi gelombang S secara intensip dimulai sejak 1970-an seperti untuk tujuan eksplorasi (Garotta, 1982), studi gelombang P dan S dimaksudkan dalam identifikasi lithologi batuan dan estimasi sifat fisik batuan, khususnya dalam kaitannya dengan estimasi sifat fisik fluida dalam sedimen. Salah satu cara untuk menggambarkan sifat batuan adalah dengan menganalisis hubungan antara Modulus Bulk yang diperoleh dari nilai kecepatan gelombang $\mathrm{P}$ dan $\mathrm{S}$ dengan nilai porositas batuan dan saturasi air.

Dalam studi ini dimaksudkan untuk melihat pengaruh porositas dan saturasi air terhadap parameter Modulus Bulk berdasarkan analisis data seismik refraksi dalam usaha pemecahan masalah geoteknik dan lingkungan. Adapun tujuan dalam penelitian ini adalah menganalisis seberapa besar pengaruh porositas dan saturasi air terhadap parameter Modulus Bulk berdasarkan analisis data seismik refraksi pada daerah Soekarno Hatta Palembang. Dan dalam penelitian ini diharapkan dapat memberikan informasi mengenai 
pengaruh porositas dan saturasi air terhadap parameter Modulus Bulk berdasarkan analisis data seismik refraksi dalam usaha pemecahan masalah geoteknik dan lingkungan

\section{TINJAUAN PUSTAKA}

Berkas sinar seismik di dalam medium mematuhi hukum fisika pada sinar optik contohnya hukum Snellius, hukum Huygens Azas Fermat, yang secara singkat dapat dinyatakan sebagai berikut : (Sumner, 1970)

a. Hukum Snellius, yaitu :

- Gelombang datang, gelombang pantul dan gelombang bias terletak pada satu bidang

- Sudut pantul sama dengan sudut datang

- Sinus sudut bias sama dengan sinus sudut datang kali perbandingan kecepatan medium pembias terhadap kecepatan medium yang dilalui gelombang datang

- Pada sudut kritis sinus sudut datang sama dengan perbandingan kecepatan medium yang dilalui gelombang datang terhadap kecepatan medium pembias.

b. Hukum Huygens menyatakan setiap titik pada muka gelombang akan menjadi sumber gelombang baru.

c. Azas Fermat menyatakan bahwa sinar gelombang selalu melintas pada lintasan optik yang terpendek (garis lurus).

Hukum - hukum diatas mendasari penjabaran gerak perambatan gelombang seismik didalam medium, terutama yang ditinjau dari geometri perambatan gelombang.

$$
\begin{aligned}
& \frac{\sin \theta_{i}}{\sin \theta_{r}}=\frac{v_{1}}{v_{2}}=n_{21} \\
& \theta_{i}=\text { sudut sinar datang } \\
& \theta_{r}=\text { sudut sinar pantul } \\
& \quad=\text { indeks bias dari media } 2 \text { terhadap media } 1
\end{aligned}
$$

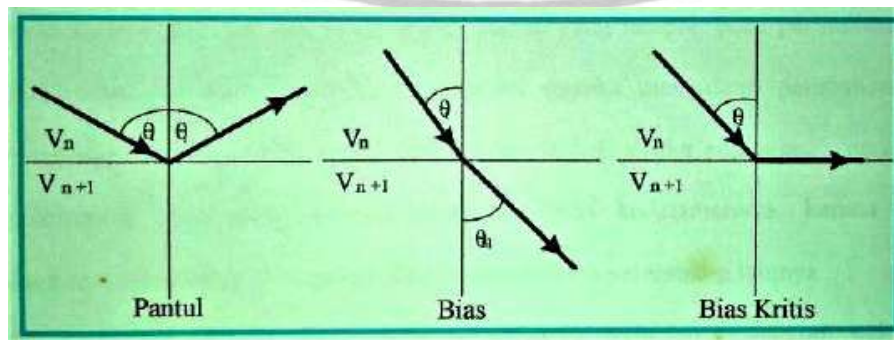

Gambar 1. Prinsip hukum Snellius (Munadi, 2000)

Metode seismik di dasarkan pada sifat penjalaran gelombang, dapat juga dikatakan bahwa penjalaran gelombang seismik terbiaskan oleh adanya gangguan media batuan dan perbedaan cepat rambat gelombang seismik (v) diantara medium batuan yang dilalui oleh gelombang (Shearer, 1999). Gangguan ini akan menjalar pada lapisan batuan bumi yang bersifat elastik dalam bentuk gelombang seismik. kemudian gaya yang bekerja pada suatu benda elastik akan mengalami tegangan dan regangan, tegangan dapat diartikan sebagai perbandingan antara gaya dengan luas penampang, secara matematis dapat dinyatakan : 


$$
S=\frac{d F}{d A}
$$

Faktor - faktor yang berpengaruh terhadap penjalaran gelombang seismik (Suantika, 2007), yaitu :

a) Sifat elastisitas dan densitas batuan

b) Porositas

c) Tekanan, baik akibat tekanan dari luar atau tekanan pori.

d) Temperatur, dimana sifat elastis berubah karena batuan mencair atau akibat pengaruh kedalaman.

e) Umur batuan, batuan yang berumur tua umumnya sangat kompak, porositasnya kecil densitas besar dan umumnya mempunyai

Macam - macam gelombang seismik berdasarkan medium penjalarannya, gelombang badan (body wave) dan gelombang permukaan (surface wave). Berdasarkan cara bergetarnya, gelombang seismik dibedakan atas dua tipe yaitu gelombang $\mathrm{P}$ (longitudinal) dan S (transversal) (Elnashai dan Sarno, 2008).

Modulus Bulk didefinisikan sebagai rasio tekanan aksial dan perubahan volume yang dihasilkan. Melalui pendekatan perambatan gelombang Modulus Bulk dapat ditulis :

$$
K=\rho\left(v_{\rho}^{2}-\frac{3}{4} v_{s}^{2}\right)
$$

Dimana $: \mathrm{K}=$ Modulus Bulk

$$
\begin{aligned}
& \rho=a v_{\rho}^{4}\left(\text { densitas } \rho \text { dalam } \mathrm{gr} / \mathrm{cm}^{3},\right. \\
& a=0,31 \text { (Geldart, 1995) }
\end{aligned}
$$

Porositas batuan adalah perbandingan volume rongga pori terhadap total batuan dan dinyatakan dalam persen. Ada dua jenis porositas batuan yaitu porositas total $\left(\phi_{t}\right)$ dan porositas efektif $\left(\phi_{e}\right)$.

Saturasi air adalah rasio antara volume pori yang terisi air $\left(V_{w}\right)$ dengan volume total pori - pori $\left(V_{p}\right)$.

$$
S=\frac{V_{w}}{V_{p}}
$$

\section{METODE PENELITIAN}

Penelitian dilakukan selama kurang lebih 3 bulan, processing data dilakukan di laboratorium Fisika dan Kimia FMIPA UNSRI, dan pengambilan data dilakukan di daerah Soekarno Hatta Palembang. Alat dan bahan dalam penelitian ini adalah untuk menentukan kecepatan, yaitu :

- 1 unit Seismograph Geometrics Smartseis ${ }^{\mathrm{TM}} \mathrm{S} 12$

- Geophone dan take out cable

- Meteran 1 buah

- Kabel konektor trigger 
- Keyboard

- Hammer dan coupling plate

- Computer PC 1 unit

Untuk pengambilan data gelombang $\mathrm{P}$ dengan cara memukulkan hammer secara vertikal pada coupling plate yang diletakkan di atas tanah secara horizontal, sedangkan posisi geophone ditempatkan secara vertikal.

Sedangkan alat dan bahan yang digunakan dalam penentuan saturasi air adalah :

- Hand bor

- Sampler

- Kantong plastik

- Spidol

\section{Model Penelitian}

Untuk pengambilan data penelitian, sistem penembakan yang digunakan adalah dengan cara off-end (forword dan reserse) dan Symtrical Split-spread. Tembakan yang akan dilakukan sebanyak 5 kali. Geophone yang dipakai sebanyak 12 buah dengan interval $2 \mathrm{~m}$. Near offset berjarak $4 \mathrm{~m}$ dan $8 \mathrm{~m}$ dengan Far offset sejauh $26 \mathrm{~m}$ dan $30 \mathrm{~m}$.

\section{Prosedur Estimasi}

1. Prosedur Estimasi Kecepatan Gelombang P

Estimasi kecepatan dilakukan dengan bantuan Program Winsism 7 buatan W-Geosoft

Geological \& Geophysical Software dengan langkah sebagai berikut :

- Konversikan format SEG-2 ke SU

- Picking First break masing-masing trace

- Baca kurva travel time antara jarak dengan waktu tempuh

- Hitung Slope kurva diatas untuk menentukan kecepatan baik gelombang P dari masing-masing lapisan

2. Estimasi Nilai Q untuk Gelombang $P(Q p)$

Estimasi nilai $Q$ dilakukan dengan bantuan program MATLAB.6.1, langkahlangkahnya sebagai berikut :

- Konversikan dari format SU ke Ascii

- Lakukan FFT untuk mengubah dari domain waktu ke domain frekuensi

- Hitung nilai Qp dengan menggunakan metode Spectral Ratio

- Lakukan prosedur diatas untuk lokasi yang berbeda

3. Estimasi Nilai Saturasi Air

Estimasi nilai Saturasi Air dilakukan dengan cara sebagai berikut :

- Timbang massa sampel asli

- Siapkan oven, masukan sampel ke dalam oven dan panaskan dengan suhu $200{ }^{\circ} \mathrm{C}$ selama \pm 4 jam

- Timbang massa kering sampel

- Sampel yang kering kemudian direndam dengan air hingga jenuh

- Timbang massa basah sampel, dan diketahui $\rho_{\text {air }}=1 \mathrm{gr} / \mathrm{m}^{3}$. 
Metode penulisan dengan didasarkan pada:

- $\quad$ Tinjauan langsung ke lokasi proyek pekerjaan untuk melihat pelaksanaan pekerjaan di lapangan

- Mencari informasi dengan para pelaksana pekerja di lokasi pekerjaan, pemilik proyek dan pengawas

- Mengumpulkan data - data di literatur dan menganalisa bahan bacaan yang diperoleh.

\section{HASIL DAN PEMBAHASAN}

\section{HASIL}

\section{Lokasi Soekarno-Hatta}

Pada lokasi ini pengambilan data seismik dilakukan pada dua line dengan $5 \mathrm{kali}$ penembakan untuk gelombang $\mathrm{P}$, yang terdiri dari 2 tembakan Off-end (forward dan reverse) untuk near offset $4 \mathrm{~m}$ dan $8 \mathrm{~m}$, dan satu tembakan Symitrical Split Spread, dengan interval geophone $1 \mathrm{~m}$, namun data yang ditampilkan pada line pertama hanya 3 penembakan, ini dikarenakan data pada 2 penembakan Off-end (forward dan reverse) untuk near offset $8 \mathrm{~m}$ tidak didapatkan.

Kurva waktu tempuh (travel time) pada line pertama untuk gelombang $\mathrm{P}$ dapat kita lihat pada gambar 1 berikut ini :

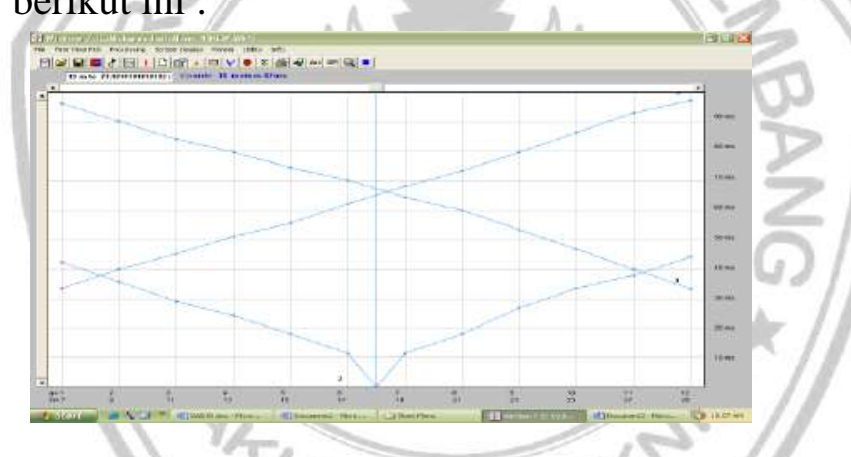

Gambar 2 Kurva waktu tempuh gelombang P pada Line pertama

\section{Lokasi Soekarno Hatta}

Pada gambar memperlihatkan estimasi harga kecepatan masing-masing tembakan untuk gelombang P. Dari tabel 1 terlihat pada lapisan pertama gelombang P memiliki kecepatan antara $301 \mathrm{~m} / \mathrm{s}$ sampai dengan $328 \mathrm{~m} / \mathrm{s}$, sedangkan kecepatan lapisan kedua antara $342 \mathrm{~m} / \mathrm{s}$ sampai $373 \mathrm{~m} / \mathrm{s}$.

Tabel 1. Harga Kecepatan Gelombang P pada Line Pertama Lokasi Soekarno Hatta

\begin{tabular}{|c|c|c|c|c|}
\hline No & $\begin{array}{c}\text { No } \\
\text { Lintasan }\end{array}$ & Konfigurasi Tembakan & $\begin{array}{c}\mathbf{V}_{\mathbf{P}} \text { Lapisan I } \\
(\mathbf{m} / \mathbf{s})\end{array}$ & $\begin{array}{c}\mathbf{V}_{\mathbf{P}} \text { Lapisan II } \\
(\mathbf{m} / \mathbf{s})\end{array}$ \\
\hline 1 & 0001 & Off-end Forward (No:4m) & 328 & 355 \\
\hline 2 & 0002 & Symetrical Split Spread & 301 & 373 \\
\hline 3 & 0003 & Off-end Reverse (No:4m) & 303 & 342 \\
\hline & Kecepatan & Rata - rata & $\mathbf{3 1 0 , 6 7}$ & $\mathbf{3 5 6 , 6 7}$ \\
\hline
\end{tabular}

Harga faktor kualitas (Q) pada semua lokasi dan lintasan dalam penelitian ini ditentukan berdasarkan analisis spektrum dengan metode spektral rasio. 
Harga faktor kualitas (Q) pada line pertama lokasi I ini dapat dilihat pada tabel. Dari tabel tersebut harga $Q$ rata-rata pada lapisan pertama harganya lebih besar dari pada lapisan kedua.

Tabel 2. Harga Faktor Kualitas (Q) pada Line Pertama Lokasi I

\begin{tabular}{|c|c|c|c|}
\hline Lapisan & Qp 0001 & Qp 0002 & Qp 0003 \\
\hline & 36,01 & 35,52 & 31,79 \\
& 35,78 & 37,33 & 23,14 \\
Lapisan I & 39,78 & 30,94 & 34,03 \\
& 38,26 & 34,22 & 35,55 \\
& & 36,65 & 33,32 \\
\hline Rata-rata & $\mathbf{3 7 , 4 6}$ & $\mathbf{3 4 , 9 3}$ & $\mathbf{3 1 , 5 7}$ \\
\hline
\end{tabular}

Kurva waktu tempuh (travel time) pada line kedua untuk gelombang P diperlihatkan pada gambar 2 berikut ini :

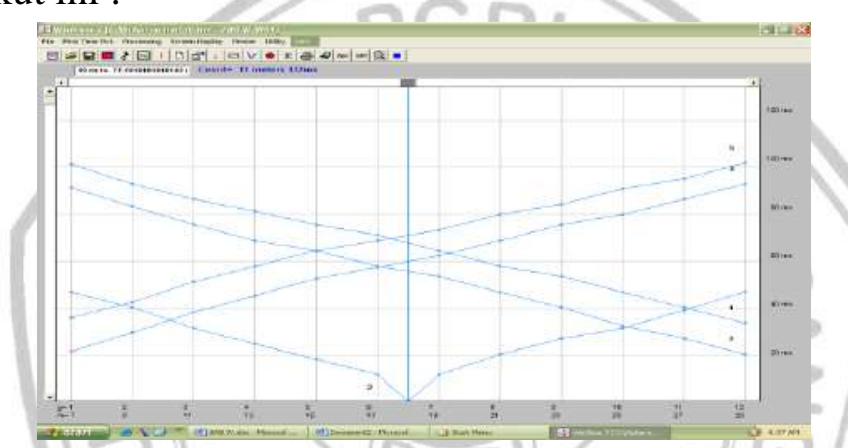

Gambar 3. Kurva waktu tempuh untuk gelombang P pada Line Kedua Lokasi Soekarno Hatta

Harga kecepatan dari masing-masing tembakan pada line ini dapat dilihat pada tabel 3 berikut :

Tabel 3. Harga Kecepatan Gelombang P Line Kedua Lokasi Soekarno Hatta

\begin{tabular}{|c|c|c|c|c|}
\hline No & No Lintasan & Konfigurasi Tembakan & $\begin{array}{c}\mathbf{V}_{\mathbf{P}} \text { Lapisan I } \\
(\mathbf{m} / \mathbf{s})\end{array}$ & $\begin{array}{c}\mathbf{V}_{\mathbf{P}} \text { Lapisan II } \\
(\mathbf{m} / \mathbf{s})\end{array}$ \\
\hline 1 & 0010 & Off-end Forward (No:8m) & 316 & 333 \\
\hline 2 & 0011 & Off-end Forward (No:4m) & 304 & 312 \\
\hline 3 & 0012 & Symetrical Split Spread & 282 & 314 \\
\hline 4 & 0013 & Off-end Reverse (No:4m) & 271 & 336 \\
\hline 5 & 0014 & Off-end Reverse (No:8m) & 293 & 363 \\
\hline & Kecepatan & Rata-rata & $\mathbf{2 9 3 , 2 0}$ & $\mathbf{3 3 1 , 6 0}$ \\
\hline
\end{tabular}

Untuk harga faktor kualitas (Q) pada line kedua ini yang didapatkan berdasarkan metode spektral rasio dapat di lihat pada tabel 4, dimana harga $Q_{P}$ rata-rata pada lapisan pertama lebih kecil jika di bandingkan dengan lapisan kedua. 
Tabel 4. Harga Faktor Kualitas (Q) Line Kedua Lokasi Soekarno Hatta

\begin{tabular}{|c|c|c|c|c|c|}
\hline Lapisan & Qp 0010 & Qp 0011 & Qp 0012 & Qp 0013 & Qp 0014 \\
\hline & 20,22 & 41,93 & 34,85 & 36,28 & 20,13 \\
& 32,54 & 41,15 & 40,88 & 36,73 & 49,64 \\
Lapisan I & 31,33 & 37,67 & 36,74 & 34,56 & 54,25 \\
& 26,69 & 34,43 & 33,90 & 31,82 & 27,21 \\
& 30,43 & 30,70 & 34,60 & 37,67 & 30,27 \\
\hline Rata-rata & $\mathbf{2 8 , 2 4}$ & $\mathbf{3 7 , 1 7}$ & $\mathbf{3 6 , 1 9}$ & $\mathbf{3 5 , 4 1}$ & $\mathbf{3 6 , 3 0}$ \\
\hline & 62,04 & 81,92 & 105,60 & 93,17 & 97,73 \\
& 109,75 & 93,73 & 94,58 & 81,01 & 70,39 \\
Lapisan II & 90,36 & 93.05 & 99,54 & 89,04 & 71,63 \\
& 109.96 & 80,50 & 105,71 & 103,26 & 89,49 \\
& 80,91 & & & 99,51 & 97,56 \\
\hline Rata-rata & $\mathbf{9 0 , 6 1}$ & $\mathbf{8 7 , 3 0}$ & $\mathbf{1 0 1 , 3 6}$ & $\mathbf{9 3 , 2 0}$ & $\mathbf{8 5 , 3 6}$ \\
\hline
\end{tabular}

\section{Saturasi Air}

Pada tabel nilai saturasi air untuk lokasi Soekaro Hatta. Pada lokasi ini ada 33 sampel dari 11 titik, untuk setiap titik diambil 3 sampel. Dari sampel tersebut didapatkan nilai saturasi air rata-ratanya untuk setiap titik pada lokasi Soekaro Hatta. Nilai rata-rata keseluruhannya pada lokasi Soekarno Hatta sebesar 0,53.

Tabel 5. Nilai Saturasi Air Pada Lokasi Soekarno-Hatta

\begin{tabular}{|c|c|c|c|c|c|c|}
\hline No & $\begin{array}{c}\text { Massa Asli } \\
(\mathbf{g r})\end{array}$ & $\begin{array}{c}\text { Massa setelah } \\
\text { direndam }(\mathbf{g r})\end{array}$ & $\begin{array}{c}\text { Massa di } \\
\text { Oven }(\mathbf{g r})\end{array}$ & $\begin{array}{c}\text { Volume Air } \\
\left(\mathbf{m}^{\mathbf{3}}\right)\end{array}$ & $\begin{array}{c}\text { Volume } \\
\text { pori/air' } \mathbf{( m}^{\mathbf{3}} \mathbf{)}\end{array}$ & $\begin{array}{c}\text { Saturasi } \\
\text { air }\end{array}$ \\
\hline 1 & 15,55 & 17,47 & 13,25 & 2,29 & 4,21 & 0,54 \\
\hline 2 & 14,87 & 18,92 & 12,28 & 2,59 & 6,63 & 0,39 \\
\hline 3 & 5,015 & 6,88 & 3,22 & 1,79 & 3,66 & 0,48 \\
\hline 4 & 26,68 & 30,69 & 23,14 & 3,54 & 7,55 & 0,47 \\
\hline 5 & 16,78 & 19,68 & 14,47 & 2,31 & 5,20 & 0,44 \\
\hline 6 & 17,84 & 20,73 & 15,06 & 2,77 & 5,66 & 0,49 \\
\hline 7 & 17,10 & 18,65 & 14,22 & 2,87 & 4,42 & 0,65 \\
\hline 8 & 13,31 & 15,06 & 10,96 & 2,35 & 4,10 & 0,57 \\
\hline 9 & 11,27 & 15,81 & 4,09 & 7,17 & 11,72 & 0,61 \\
\hline 10 & 9,19 & 10,13 & 7,16 & 2,02 & 2,96 & 0,68 \\
\hline 11 & 9,52 & 10,77 & 7,91 & 1,61 & 2,86 & 0,56 \\
\hline & & \multicolumn{7}{c}{ Rata-rata } & $\mathbf{0 , 5 3}$ \\
\hline
\end{tabular}




\section{PEMBAHASAN}

\section{Lokasi JI. Soekarno-Hatta}

Dalam analisis sifak fisik batuan, kecepatan penjalaran gelombang seismik merupakan salah satu parameter penting dan besarnya kecepatan ditentukan oleh jenis gelombang, sifat elastis, dan rapat massa medium batuan tersebut. Disamping itu, faktor lain yang juga mempengaruhi dalam analisis lanjut yaitu faktor redaman atau atenuasi yang diinplementasikan dalam faktor kualitas (Q) batuan.

Faktor kualitas (Q) merupakan kemampuan batuan dalam merambatkan atau meloloskan energi yang dipancarkan dari sumber seismik, dan sifat fisik batuan yang dilaluinya di duga mempengaruhi besar kecilnya nilai $Q$ faktor, seperti porositas, kerapatan, saturasi fluida, tekanan dan lain-lain.

Dari data lapangan didapatkan harga-harga kecepatan untuk gelombang P. Pada lokasi I line pertama (tabel 1), kecepatan rata-rata pada lapisan pertama nilainya lebih rendah dari pada lapisan kedua, yaitu sebesar 310,67 m/s dan untuk lapisan kedua sebesar 356,67 $\mathrm{m} / \mathrm{s}$. Begitu juga pada line kedua (tabel 3), dimana pada lapisan pertama kecepatan rataratanya sebesar 293,20 m/s, dan lapisan kedua sebesar 331,60 m/s. Hal ini merupakan indikator dimana batuan pada lapisan pertama tersaturasi air lebih tinggi jika dibandingkan lapisan kedua yang lebih kompak.

Pada gambar 5 merupakan crossplot hubungan antara kecepatan dengan tingkat saturasi air, dimana saat gelombang seismik melewati batuan yang tersaturasi air tinggi maka kecepatannya akan turun, sehingga dapat disimpulkan hubungan antara saturasi air dengan kecepatan berbanding terbalik.

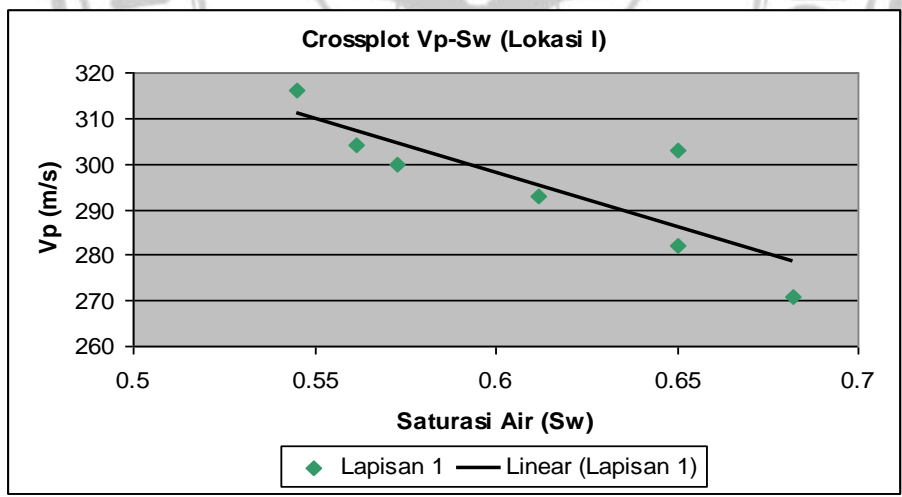

Gambar 5. Crossplot Sw dan Kecepatan (Vp) Lapisan pertama

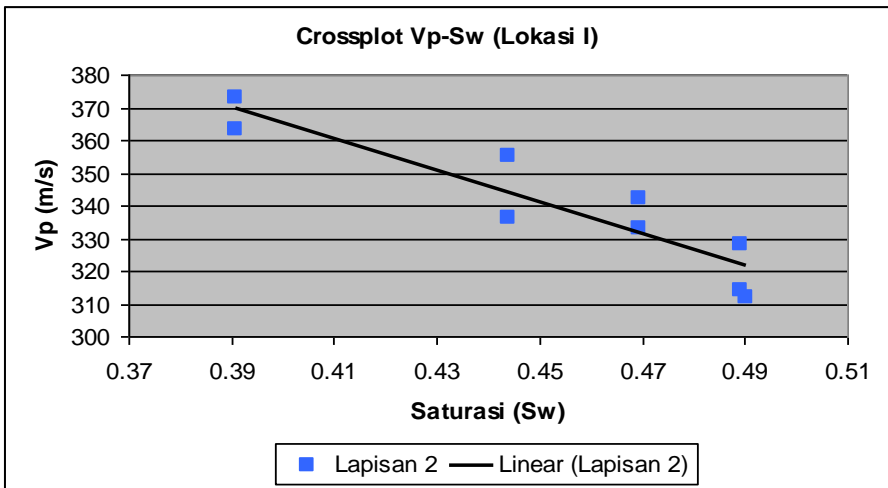

Gambar 6. Crossplot Sw dan Kecepatan (Vp) Lapisan kedua 


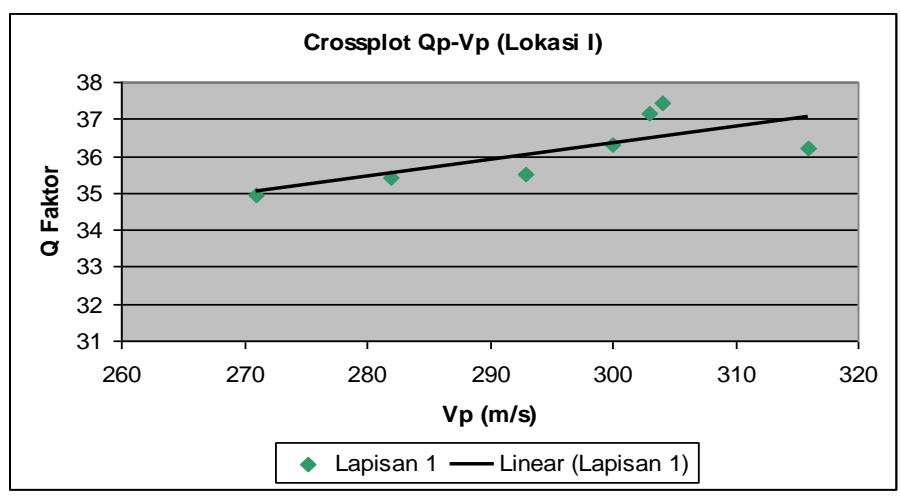

Gambar 7. Crossplot Q Faktor dan Kecepatan (Vp) Lapisan Pertama

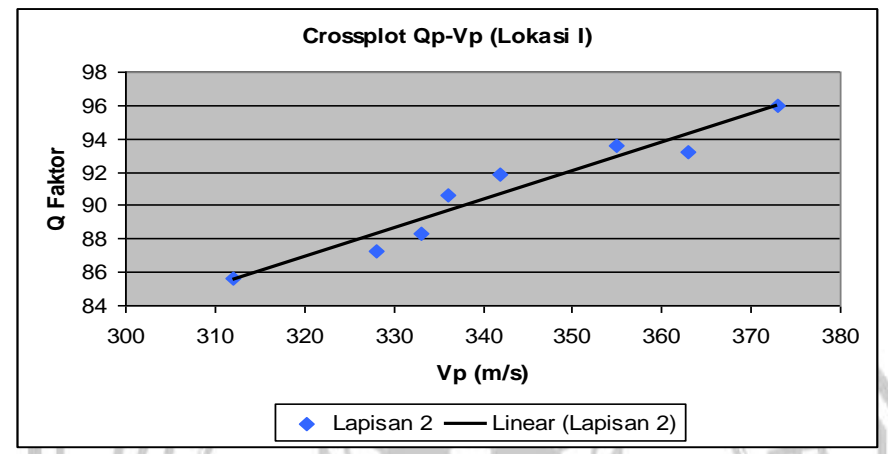

Gambar 8. Crossplot Q Faktor dan Kecepatan (Vp) Lapisan kedua

Crossplot untuk gambar 7 dan 8 diatas menunjukkan hubungan antara kecepatan gelombang seismik yang menjalar dengan harga faktor $Q$ batuannya. Dari gambar diatas diketahui bahwa semakin besar kecepatan maka akan semakin besar pula harga $\mathrm{Q}$ faktornya. Pada lapisan pertama harga nilai kecepatannya lebih rendah dibandingkan lapisan kedua, ini menunjukkan bahwa pada lapisan kedua sifat fisik batuannya jauh lebih kompak dibandingkan lapisan pertama.

Untuk nilai Q faktornya dapat kita lihat pada tabel 2 dan tabel 4 dimana harga Q ratarata untuk lapisan pertama pada setiap tembakan bernilai lebih rendah dibandingkan dengan lapisan kedua.

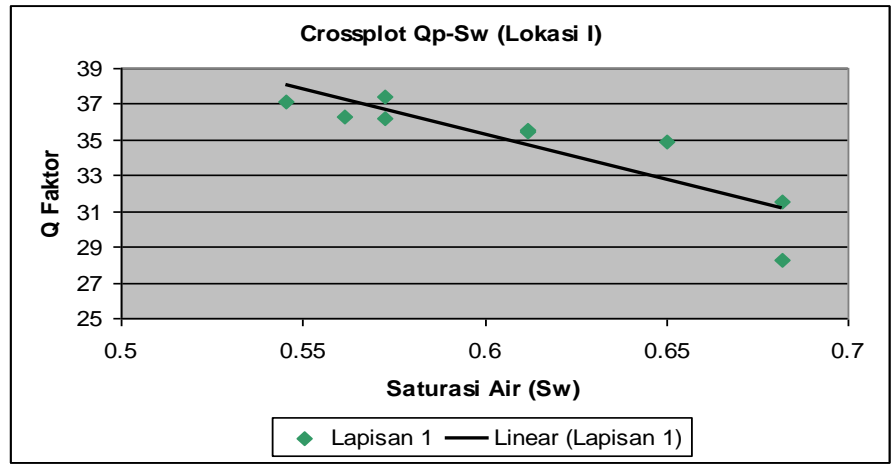

Gambar 9. Crossplot Sw dan Q Faktor untuk Lapisan pertama 


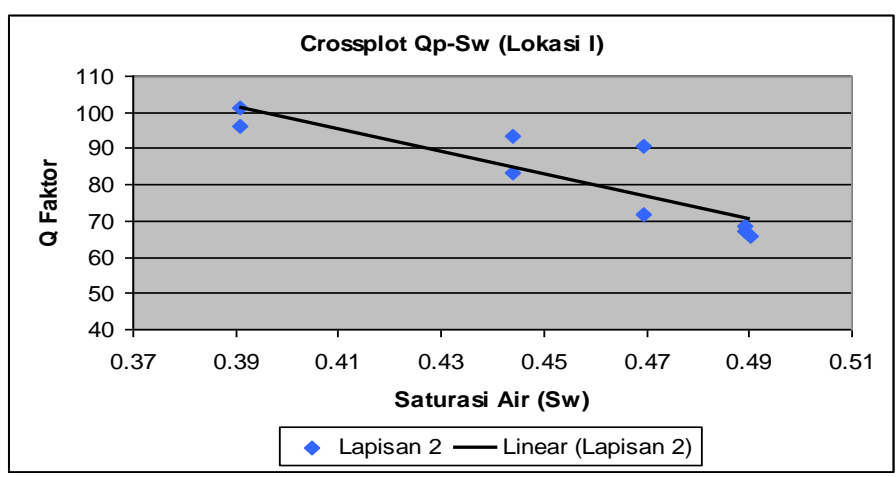

Gambar 10. Crossplot Sw dan Q Faktor untuk Lapisan kedua

Dari gambar 9 dan 10 dapat dilihat bahwa nilai $\mathrm{Q}$ faktor berbanding terbalik dengan nilai saturasi air. Ini menunjukkan bahwa energi gelombang seismik mengalami atenuasi (peredaman) oleh batuan yang tersaturasi air, akibatnya nilai kecepatan gelombang menjadi rendah. Sementara itu, Q faktor sendiri merupakan kemampuan batuan dalam merambatkan atau meloloskan energi geombang seismik yang dipancarkan dan nilainya berbanding terbalik dengan atenuasi. Sehingga, saat tingkat saturasi air tinggi maka di dapatkan nilai $Q$ faktornya rendah, dan sebaliknya, saat tingkat saturasi airnya rendah maka $\mathrm{Q}$ faktornya akan bernilai tinggi.

\section{KESIMPULAN}

Dari analisis dan pembahasan hasil penelitian, maka sapat disimpulkan sebagai berikut :

1. Dari hasil crossplot antara kecepatan dan saturasi air menunjukkan pada lapisan pertama $(310,67 \mathrm{~m} / \mathrm{s})$ harga kecepatan penjalaran gelombang seismik lebih besar dari pada lapisan kedua $(356,67 \mathrm{~m} / \mathrm{s})$, sedangkan tingkat saturasi airnya pada lapisan pertama lebih rendah dari pada lapisan kedua. Hal ini menunjukkan bahwa terjadinya peredaman (atenuasi) gelombang seismik yang menjalar pada batuan lapisan pertama lebih rendah dari pada lapisan kedua yang tersaturasi air lebih besar.

2. Dari hasil crossplot antara kecepatan dan Q faktor menunjukkan bahwa semakin besar kecepatan penjalaran gelombang seismik pada batuan maka akan semakin besar pula harga Q faktornya

3. Dari hasil crossplot antara saturasi air dan Q faktor pada lokasi terlihat bahwa pada lapisan yang tingkat saturasi airnya lebih tinggi maka harga $\mathrm{Q}$ faktor batuannya akan semakin rendah. Hal ini menunjukkan bahwa tingkat saturasi air batuan mempengaruhi besar kecilnya harga $\mathrm{Q}$ faktor yang nilainya berbanding terbalik dengan atenuasi (redaman). 


\section{DAFTAR PUSTAKA}

H.R.Burger (1992)., Dalam : Sutopo,. (2003).,Studi Konstanta Elastis dan Faktor Kualitas (Q-Faktor) berbagai Batuan Sendimen Dekat Permukaan Menggunakan Gelombang P dan SH. Departemen Geofisika dan Meteorologi. ITB..

Setiawan, dkk., (2003), Pengukuran Faktor Kualitas Gelombang Elastik (Qp, Qsh, Qsv) untuk Karakteristik Retakan Anistropi Batuan Karbonat : Studi Kasus Lapangan di Ceteurep, Proceeding Joint Convention Jakarta 2003 (JCJ-2003), IAGI-HAGI.

Sutopo \& Awali P., (2004) Studi Gelombang P dan SH dari Data Refraksi pada lapisan Jenuh Air. Joint Convention 2003 (JCJ-2003). IAGI-HAGI.

Walsh, J.B., (1996), Seismic Wave Attenuation in Rock due to Friction, Journ. Geoph. Res $712591-2599$.

Winkler Kenneth W. \& A. Nur., (1981), Seismic Attenuation : Effect of Pure Fluids and Frictional Slinding. Geophysics. Vol 47.

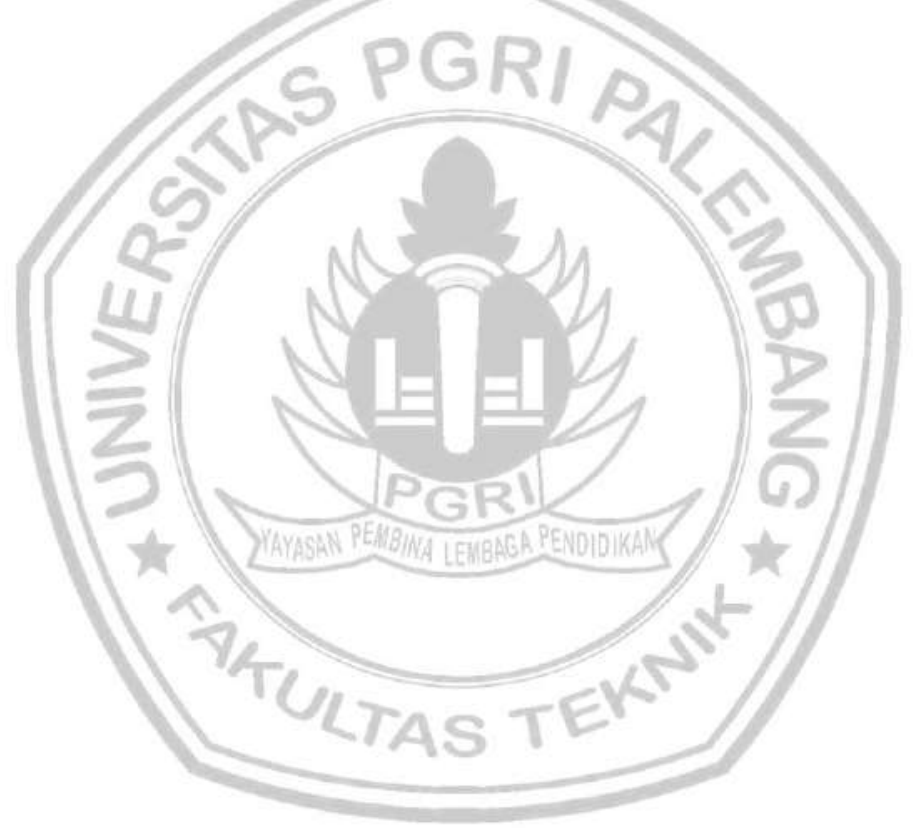

